\title{
Sustained Myrmecophagy in Nigerian Chimpanzees: Preferred or Fallback Food?
}

\author{
Volker Sommer1,2, Umaru Buba2,3, Goncalo Jesus ${ }^{1,2}$, Alejandra Pascual-Garrido 2,4 \\ ${ }^{1}$ Department of Anthropology, University College London, London WC1 E6BT, United
}

Kingdom

${ }^{2}$ Gashaka Primate Project, Serti 663 001, Taraba State, Nigeria

${ }^{3}$ Department of Biological Sciences, Taraba State University, Jalingo PMB 1167, Nigeria

${ }^{4}$ Leverhulme Trust Early Career Fellow, School of Archaeology, University of Oxford, Dyson

Perrins Building, South Parks Road, Oxford OX1 3QY, United Kingdom.

Number of text pages plus bibliography: 32, Number of figures: 3 , Number of tables: 0 , Number of graphs: 9 , Number of charts: 0 .

Abbreviated title: Sustained myrmecophagy in chimpanzees

Keywords: insectivory; nutrition; army ants

Corresponding person: Alejandra Pascual-Garrido, School of Archaeology, University of Oxford, Dyson Perrins Building, South Parks Road, Oxford OX1 3QY, United Kingdom, Telephone number: +25568326 8654. Email: alejandra.pascual-garrido@rlaha.ox.ac.uk Grant Sponsorship: Fundação para a Ciência e Tecnologia / Portugal; Nigeria Biodiversity Programme of the North of England Zoological Society, Chester Zoo / UK; The Leverhulme Trust / UK.

\begin{abstract}
Objective: At some sites across Africa, chimpanzees consume army ants, often aided by stick-tools, although consumption frequencies vary greatly. Other populations do not eat these insects at all, despite apparent abundance. The relative importance of myrmecophagy
\end{abstract}


for chimpanzee diet therefore remains unclear. Major functional hypotheses consider army ants either as a preferred food or a fallback fare when preferred foods are scarce. We test these hypotheses for chimpanzees at Gashaka / Nigeria, where chimpanzees consume army ants much more frequently than elsewhere.

Methods: Long-term records on seasonality of climate and availability of fruit as the chimpanzees' preferred staple food are compared to rates of recovered army ant dipping wands and army ant remains in faeces.

Results: Despite strict seasonality in terms of rainfall and fruit abundance, myrmecophagy does not negatively correlate with fruit availability. Instead, ant eating is sustained year round at high levels, with $44 \%$ of faeces containing remains.

Conclusions: Results contradict the fallback hypothesis and support the hypothesis of ants as preferred food. Nevertheless, ant-meals can normally provide only negligible amounts of nutrients. At Gashaka, however, nutritional yield may be significant, given that an ant dipping session provides $13 \mathrm{mg}$ of dry weight to a chimpanzee. The species exclusively eaten here, Dorylus rubellus, might be particularly aggressive, thus resulting in greater harvesting success than elsewhere. Army ants may thus serve as a diet supplement or complement in terms of macro or micronutrients. We also speculate that dietary choices likely contain social dimensions that may strengthen group identity.

\section{INTRODUCTION}

At some sites across Africa, chimpanzees (Pan troglodytes) consume army ants (genus Dorylus), often aided by stick-tools, although the frequency of consumption varies greatly (Schöning et al., 2008). Populations elsewhere do not eat these insects at all, despite apparent abundance. Given this variability, there is no consensus about the importance of 
myrmecophagy for chimpanzee diet, i.e., whether army ants constitute a desired food or a fallback fare.

We contribute to this debate through data on the patterns of seasonal consumption of army ants by chimpanzees at Gashaka / Nigeria. This population eats these insects with greater frequency than at any other study site, as measured by the proportion of chimpanzee faecal samples that contain ant remains (Gashaka / Nigeria 44.3\%, PascualGarrido et al., 2013; Bossou / Guinea 37.4\%, Takemoto, 2000; Seringbara / Guinea 36\%, Koops et al., 2013; Dja / Cameroon 14.5\%, Deblauwe and Janssens, 2008; Kalinzu / Uganda 8.6\%, Hashimoto et al., 2000; Kahuzi-Biega / DRC <4\%, Basabose, 2002; Gombe / Tanzania 3\%, McGrew, 1992; Assirik / Senegal 2\%, McGrew, 1992; Bwindi / Uganda 1.8\%, Stanford and Nkurunungi, 2003; Bulindi / Uganda 0.2\%, McLennan, 2011).

Primate diet, notwithstanding varying terminology (Lambert, 2007; Marshall and Wrangham, 2007; Harrison and Marshall, 2011), can be broken down into two major categories. (a) Preferred foods are selected disproportionately often, relative to abundance. They do not necessarily constitute a large portion of the diet. Instead, as foods rich in nutrients and energy, they may be rare. Thus, preferred foods generally require a long search time but short processing time. Accordingly, these high-quality foods drive harvesting adaptations, mainly at the behavioural level (e.g., fruits, accessed through fission-fusion social systems; nuts, insects, accessed through tools). (b) Fallback foods are eaten in greater amounts when preferred foods are unavailable. They can form a large portion of the diet, if preferred foods are unavailable. Accordingly, they may be further classified into staple fallback (important, eaten year-round, up to $100 \%$ of the diet) and filler fallback (may not be eaten for long periods, never 100\% of the diet). Such foods tend 
to be abundant and therefore require low search time, albeit high processing time. Therefore, these low-quality foods drive processing adaptations, mainly at the level of anatomy (e.g., accessing leaves and bark requires specialized dental or digestive traits).

The four subspecies of chimpanzee (for the following, see Boesch et al., 2002; McGrew, 2004; Caldecott and Miles, 2005) inhabit varied habitats (rainforests, woodlandsavannah, gallery forests, mosaic habitats with plantations and grassland). These apes form communities of typically $20-100$ members that range over $5-38 \mathrm{~km}^{2}$ in forests and $25-560$ $\mathrm{km}^{2}$ in open environments. Chimpanzee diet varies considerably across populations. Nevertheless, there is agreement that the preferred food is ripe fruit (56-71\% of foraging time). Filler fallback food is represented by leaves (18-21\%) as well as bark, terrestrial herbs and pith (11-23\%). Figs are the major staple fallback food (up to 91\%, according to Harrison and Marshall, 2011), although their role is disputed, as figs are a preferred food at some sites (e.g., Dutton and Chapman, 2015). The importance of animal matter (McGrew, 1992; Pruetz 2006) is likewise debated. In any case, at some sites, vertebrates of at least 25 species are preyed upon (0.3-6\%). To various degrees, chimpanzees also exploit colonies of eusocial insects such as termites, ants and bees to consume imagos, brood or honey often aided by tools.

There is no agreement if and which types of insectivory reflect a desired nourishment or a fallback fare. Data on seasonality are particularly suitable to test nutritional hypotheses as one can compare fluctuations in the availability of fruit as the preferred food with rates of insectivory. A positive correlation - i.e., when fruit becomes scarce, insect harvesting goes up - would support the compensation hypothesis that insects are a fallback fare. 
A comprehensive review of seasonality in chimpanzee insect consumption has not been conducted. Nevertheless, pronounced peaks seem to be the rule. For example, (i) Fongoli / Senegal: termites are preferentially consumed during the late dry to early wet season (Bogart and Pruetz, 2011); (ii) Assirik / Senegal: termite consumption shows "marked seasonality" (McGrew, 1992: 157); (iii) Gombe / Tanzania: termites are eaten in all months, but consumption peaks sharply when rains set in (McGrew et al., 1979; McGrew, 1992); (iv) Mahale / Tanzania: Hemiptera (true bugs) and Isoptera "are substantially consumed only seasonally" (Nishida and Hiraiwa, 1982: 93); (v) Mahale / Tanzania: Camponotus and Crematogaster ants are eaten year round, but significantly less so in April and May (Nishida and Hiraiwa, 1982: 93).

These exemplary accounts highlight the problem that seasonal insectivory might not automatically discount the hypothesis of insects as preferred food, because their life-style may make them exclusively or more easily available at certain periods (McGrew, 1992). For example, baboons at Gombe / Tanzania consume termites only when the rainy season begins and winged forms emerge en masse. The sympatric chimpanzees, on the other hand, extend this termite-harvesting period for several weeks. Above-ground construction of termite mounds increases during the rains, when wet soil is moulded more easily and many workers come close to the surface (McGrew et al., 1979). The chimpanzees at this time famously use tools to "fish" workers out of their underground tunnels. Humans scrape mounds open and lure the insects with kerosene lamps to the surface, to then scoop up the "milling mass" (Teleki, 1974: 591). This indicates that insects can be a sought-after resource - despite the fact that primates cannot always easily obtain them because of constraints imposed by the insects' biology or own extraction techniques. 
Still, seasonal consumption of insects can also reflect a role as fallback food. For example, bears in boreal forests frequently dig up ant colonies in spring, when plant food quality is low. They shift to fruits as these become abundant in midsummer, suggesting "that ants are used when other, more nutritious foods are not available" (Swenson et al., 1999: 552).

Clearly, given considerable differences in the ecology of chimpanzee habitats, there is no single answer to the question if insects constitute a preferred food or a fallback food. We test these competing hypothesis specifically, against long-term data on the behaviour and ecology of Nigerian chimpanzees at Gashaka-Kwano in Nigeria (Sommer and Ross, 2011a). Here, chimpanzees prey upon colonies of honeybees, stingless bees, arboreal ants and army ants, while neglecting termites. We previously described insect prey taxonomy as well as the elementary technology associated with insectivory (Fowler and Sommer, 2007; Schöning et al., 2007; Fowler et al., 2011; Pascual-Garrido et al., 2012; Sommer et al. 2012). For army ants in particular, we have earlier reported how chimpanzee predation success is related to their defensive and migratory behaviour (Allon et al., 2012; Pascual-Garrido et al., 2013). Here, we focus on the annual patterns of army ant gathering and relate them to habitat ecology with the aim to assess the importance of myrmecophagy in the diet of the rarest and least known chimpanzee subspecies.

\section{MATERIALS AND METHODS}

\section{Study site}

Our research took place in Gashaka Gumti National Park (GGNP; Dunn, 1999; Sommer and Ross, 2011a), Nigeria's largest national park with 6,731 $\mathrm{km}^{2}\left(06^{\circ} 55^{\prime}-08^{\circ} 13^{\prime} \mathrm{N}, 11^{\circ} 13^{\prime}\right.$ $\mathrm{N}-12^{\circ} 11^{\prime} \mathrm{E}$ ). GGNP demarcates the northern edge of the Cameroonian Highlands and is 
divided into the relatively flat northern Gumti sector and the mountainous southern Gashaka sector. Habitat types include Guinea savannah-woodland, riverine and gallery forest, lowland rain forest, montane forest and montane grassland. The Gashaka Primate Project maintains a field station at Kwano (583 m; 07ำ $19^{\prime} \mathrm{N}-011^{\circ} 35^{\prime} \mathrm{E}$ ), 11 aerial $\mathrm{km}$ from the nearest village of Gashaka.

\section{Climate}

The weather at Kwano is characterised by an alternation between an annual wet and dry season, with corresponding fluctuations in temperature, humidity and vegetation cover (Fig. 1). From 2001-2008, yearly mean rainfall was 1,973 mm (2001: 1,683; 2002: 2,056; 2003: no data; 2004: 2,337; 2005: 1,945; 2006: 2,279; 2007: 1,786; 2008: 1,726). Mean monthly humidity at sunset fluctuated between 59\% (February) and 87\% (September). The mean minimum temperature was $20.9^{\circ} \mathrm{C}$, the coolest recorded temperature $14^{\circ} \mathrm{C}$ (January, December), the mean maximum $31.9^{\circ} \mathrm{C}$, and the hottest day on record $43^{\circ} \mathrm{C}(\mathrm{March} 2001)$ (Sommer and Ross, 2011b).

[Figure 1 here]

\section{Gashaka-Kwano chimpanzee community}

The wider Gashaka region harbours the largest surviving population of the NigeriaCameroon chimpanzee (Pan troglodytes ellioti aka vellerosus; Morgan et al., 2011). Research concentrates on the Gashaka-Kwano community in the surroundings of the field station, which has about 35 members that range over approximately $26 \mathrm{~km}^{2}$ (Sommer et al., 2004). The chimpanzees are regularly encountered but not fully habituated to human observers. 
Patchy food distribution causes chimpanzee communities to split into smaller parties to travel and sleep (Hohmann et al., 2006b). At times, new members may join these parties ("fusion") or split from them ("fission"). It is customary to denote diurnal units as "day parties" or "foraging parties" (although these sub-groups also rest and socialise together). Nocturnal units where individuals construct sleeping platforms in close proximity to each other are commonly termed "sleeping parties" (although they are not always sleeping) or "nest groups". To avoid semantic confusion with "nests" of insects, diurnal and nocturnal sub-units are labelled here as day groups and night groups.

Sizes of night groups were determined from counts of fresh chimpanzee sleeping platforms that constituted a nesting group $(n=277 ; 2001$ : 102; 2002: 69; 2003: 13; 2005 : 17; 2007: 27; 2008: 49). Gashaka-Kwano chimpanzees very rarely construct arboreal day nests. We are therefore reasonably confident that our counts provide reliable figures. Still, these records capture only weaned individuals, as mothers share nests with their unweaned infants, who constitute $9-10 \%$ of the members of the Gashaka-Kwano community (Sommer et al., 2004; GJ, unpubl.).

\section{Army ants as chimpanzee prey}

Gashaka-Kwano chimpanzees prey practically exclusively on the army ant Dorylus rubellus, given that only a single faecal sample was ever found to contain another taxon $(D$. gribodoi) (Allon et al., 2012). D. rubellus is considered an epigaeic species that raids on the ground and up in the vegetation. Their foraging swarms, easily $10 \mathrm{~m}$ wide, typically catch spiders, stick insects, slugs, caterpillars, crickets, beetles, grasshoppers, woodlice, other ants, earthworms or crabs (Schöning, 2005).

\section{Army ant dipping wands as harvesting tools}


Indirect evidence suggests that Gashaka-Kwano chimpanzees obtain army ants very rarely from trails but predominantly from the insect nests (Schöning et al., 2007). Instead of employing specific search strategies based on visual cues or spatial memory, the apes seem to encounter these underground burrows opportunistically (Pascual-Garrido et al., 2013; see below). The ants respond aggressively upon disturbance, quickly attacking a foreign object such as a wooden tool (Fig. 2). Accordingly, Gashaka-Kwano chimpanzees harvest army ants with dipping wands (mean length $83.8 \mathrm{~cm}$, mean diameter $5.1 \mathrm{~mm}, n=360$; Fowler et al., 2011). An atelier is the assemblage of tools left behind by the chimpanzees after they harvested the insects of a given colony.

Researchers can predictably recover tools with which chimpanzees have targeted beehives and arboreal ants through repeated visits of the insect nests, as these are stationary. However, army ant dipping wands are only found if searched for on the forest floor, given the subterranean nesting and nomadic lifestyle of these insects. On average, a colony remains in a given burrow for 11.4 days (median 9, range $2-36, \mathrm{SD}=8.3, n=9$ ), after which the ants migrate on average $119 \mathrm{~m}$ (median 113, range 46-261 $\mathrm{m}, \mathrm{SD}=53.9, n=43$ ) to a new site (Pascual-Garrido et al., 2013). The likelihood of finding dipping wands thus depends on search time.

From 2001-2008, we had a system of surveys in place, where typically a single observer (and sometimes teams of two to three individuals) went on predetermined routes that systematically covered sections of the Gashaka-Kwano chimpanzee home range. Observers generally followed a rota of walking and pausing, while recording sightings of primates and other large mammals as well as recovering abandoned chimpanzee tools. Surveys encompassed all hours of the day and all months of the year (2000-2001, 2005- 
2008 ; total $=17,487$ hours). Survey records allow us to convert absolute numbers of recovered ant dipping tools into monthly frequencies (cf. Sanz et al., 2014).

[Figure 2 here]

\section{Chimpanzee faecal sample collection}

The ground beneath sleeping platforms was checked for faecal remains. These are produced in the early morning before the tree is vacated. It was generally possible to assign a specific dropping to a particular nest. Most samples obtained for this study were from fresh platforms constructed during the previous night. Faecal piles were brought back to the field station, dried in the sun for 3 days, and then broken up for inspection. The presence and type of ingesta was assessed through macroscopic inspection (cf. Hohmann et al., 2006a; Schöning et al., 2007). In this way, 660 chimpanzee faecal samples were processed under the supervision of Andrew Fowler ( $n=254$, March 2001-December 2004), Darren Ellis ( $n=127$, January-April 2005), and APG and UB ( $n=279$, February 2007-March 2008). The number of analysed samples varied for specific types of ingesta.

\section{Army ant remains in chimpanzee faeces}

For $n=660$ chimpanzee faecal samples collected from 2001-2008, we recorded whether or not they contained army ant remains. The absolute number of ant heads was counted in $n=59$ dung piles (January-April 2005; Allon et al., 2012). Counts of broken ant heads (usually only those of large workers could still be identified as such) were divided by two and added to the number of complete heads. More than a third of the samples contained fewer than 100 ants (range 3-90), three quarters not more than 700, and only every sixth sample contained more than 1000 ants (range 1344-4636). The mean number 
of heads was 576, which corresponds to $1.3 \mathrm{~g}$ dry weight. Based on experiments, we estimate that only $10.1 \%$ of originally ingested ants are found in a subsequent excretion (Allon et al., 2012). This translates to $12.9 \mathrm{~g}$ dry weight of ingested ant matter per dipping session.

\section{Fruit consumption by chimpanzees}

Direct observations reveal that fruits of trees and / or vines constitute the staple food of Gashaka-Kwano chimpanzees. Correspondingly, all inspected faecal samples contained fruit remains (Hohmann et al., 2006a). Dung samples encompassed at least 25 different species, with an average of 4.5 / month (range 1-7). A few species accounted for the majority of structured remains. A similar picture emerged at the nearby site of Ngel Nyaki, about 70 aerial $\mathrm{km}$ from Kwano. Here, P. t. ellioti chimpanzees consume fruits from at least 52 taxa (Dutton and Chapman, 2014). Faecal analyses indicate that the apes consume fruit in the same proportion as is available in the environment, notwithstanding selectivity towards particular species. At both the Ngel Nyaki and Gashaka-Kwano sites, vine fruit (genus Landolphia) constitutes a major food source, particularly between the months of March and May.

\section{Habitat phenology}

We used measurements of the abundance of tree and vine fruits in the GashakaKwano habitat as a proxy for the availability of chimpanzee staple food throughout the year. The data were generated by monitoring individual trees with a diameter at breast height (DBH) of at least $10 \mathrm{~cm}(n=985)$ and associated woody climbers $(n=815)$. These

plants grow along $8 \mathrm{~km}$ of a $4 \mathrm{~m}$ wide line transect that is a representative cross-section of 
the study area's physical features and vegetation cover $(72.3 \%$ forest, $27.7 \%$ woodland-savannah).

Field assistants visited each transect plant fortnightly over 69 months (April 2002June 2009) and recorded parameters such as the absence or presence of flowers and fruits (both ripe and unripe). In the absence of data on fruit chemistry, the distinction between "ripe" and "unripe" fruit tends to be arbitrary. However, findings for other sites suggest that chimpanzees may at times ingest substantial amounts of unripe fruit (e.g., Reynolds et al., 1998). Therefore, assessments of food abundance included all sources that produced fruit of mature size.

DBH is a good indicator of both tree height and crown diameter and thus predicts fruit bearing parts of the vegetation, including biomass and fruit number (Leighton and Leighton, 1982). The DBH measurements of fruit bearing transect trees were summed up

monthly, as were the DBH values of vine-bearing trees, given that we assume that host tree DBH correlates positively with vine fruit production. DBH sums of fruiting trees and vines were combined into a monthly fruit index that we consider to be indicative of fruit availability.

\section{RESULTS}

Our long-term data for the Gashaka-Kwano chimpanzee community in Nigeria allow us to reconstruct the interplay between the temporal and quantitative patterns of fruit availability, chimpanzee gregariousness, tool manufacture to dip for army ants and insect consumption.

Annual patterns of rainfall, fruit production and chimpanzee gregariousness 
The Gashaka-Kwano habitat sees a pronounced seasonality in rainfall and fruit production (Fig. 3).

A dry period from about mid-November to mid-April with no or very little rain coincides with the harmattan, a dusty wind that blows from the Sahara. This dry period is followed by often heavy downpours from mid-April to mid-November that constitute $97.2 \%$ of all annual precipitation (monthly values for mm rain: mean 162 , median 229 , range $0-332, \mathrm{SD}=133$; chi-square test: $X^{2}{ }_{11}>24.72, P<0.001$ ).

Fruit production of trees and vines growing on the botanical transect are likewise strictly seasonal, with a distinct peak from March till June. Per month, a mean of $9.3 \%$ of transect plants bear fruit (median 8, range 5.0-15.3, SD = 4.0). Expressed as a fraction of the total annual fruit index, this translates into a monthly mean of $8.3 \%$ (median 6.7, range 4.1-13.9, $\mathrm{SD}=3.9$; chi-square test: $X^{2}{ }_{11}>24.72, P<0.001$ ).

Chimpanzee night group sizes averaged 5.3 weaned animals (average of monthly means; median 5.3 , range $3.2-8.1, \mathrm{SD}=1.4$, absolute range $1-21, n=277$ ). Their annual fluctuation is significantly positively correlated with fruit production, given that night groups are particularly large from March to June when fruits are most abundant (Spearman's rank-order correlation: $r_{s}=0.650, P=0.026$ ).

[Figure 3 here]

\section{Manufacture of ant-dipping tools}

Chimpanzees abandoned tools at army ant colonies during any given month of a year ( $n=364$; bi-monthly proportions of annual total, controlled for survey time spent in the forest: Jan-Feb 18.5\%, Mar-Apr 19.5\%, May-Jun 12.7\%, Jul-Aug 20.8\%, Sep-Oct 20.2\%, 
Nov-Dec 8.4\%). Thus, for most parts of the year, chimpanzees produce these tools with roughly similar frequencies.

This assumption is confirmed by a calculation of the mean number of ant-dipping tools used per member of foraging sub-groups. For this, we related the monthly sizes of chimpanzee night groups to the mean monthly sizes of tool ateliers (Fig. 4). Accordingly, an individual chimpanzee employed an average of 0.6 tools (median 0.6 , range $0.4-0.9, \mathrm{SD}=$ 0.2 ), with little annual fluctuation (chi-square test: $X^{2}{ }_{11}=0.49 ; P>0.05$, ns).

[Figure 4 here]

The number of tools used per chimpanzee did not vary with seasonal patterns of fruit abundance (Fig. 5). Tool manufacture was therefore independent from the availability of the apes' main food (regression, $R^{2}=0.111, \mathrm{~N}=12, P=0.1447, \mathrm{~ns}$ ).

Thus, it is very likely that the Gashaka-Kwano chimpanzees produce dipping wands to harvest army ants at a rather steady rate.

[Figure 5 here]

\section{Army ant remains in faeces}

Chimpanzee dung samples macroscopically inspected for the presence of various faunal and floral remains ( $n=269,2007-2008)$, without exception, contained seeds. The second biggest fraction (69.1\%) was composed of other plant parts. Remains of other insects (ants, grasshoppers, bees) were restricted to $4.8 \%$ of samples, while fragments of $D$. rubellus army ants were identified in 54.6\%. On the other hand, faecal samples covering each month of the year $(n=381,2001-2005)$ were devoid of termite remains, and we never recorded discarded tools on or near termite mounds. 
Thus, every couple of days or so, Gashaka-Kwano chimpanzees can be expected to eat army ants. Binary data on the absence or presence of army ant remains in the overall sample of faeces revealed that chimpanzees consumed army ants throughout the year (Fig. 6a). The mean of monthly proportions of faeces with Dorylus remains comes to $44.3 \%$ (median 48.5, range 13.0-60.9, SD = 14.4). Values for the 10 months from MarchDecember varied comparatively little. Thus, despite lower values for January-February, the difference between months was not statistically significant (chi-square test, $X^{2}{ }_{11}=28.5, P>$ $0.05, \mathrm{~ns})$.

[Figure 6a here]

One might argue that multiple faecal samples from the same night group are not independent data points - although night groups will often incorporate members that foraged independently throughout the day (see below). We therefore randomly selected samples from each of the 161 night groups that faeces were collected from. The resulting value of $45.3 \%$ is very similar to that obtained from pooled samples.

The pooled data were also used to compare ant ingestion during the rainy season (15 March-14 November) and dry season (15 November-14 March). The resulting proportions were almost identical, with $42.9 \%$ (141 / 375) of wet season samples containing army ant remains, as compared to $40.1 \%$ (95 / 237) during the dry season ( $N$ contingency table with Yates correction, $\left.X^{2}{ }_{1}=0.38, P>0.05, \mathrm{~ns}\right)$.

To estimate the quantity of consumption across the year, we calculated the proportions of collected dung that contained none (0), few to medium amounts of ant remains $(\leq 100)$ or many fragments $(>100)$ (Fig. 6b). Again, patterns across the year were relatively consistent, because during the majority of months, faeces contained fractions of 
few to medium as well as many fragments.

[Figure 6b here]

The likelihood that faeces contained army ant remains was independent from the availability of fruit (regression, $R^{2}=0.016, n=12, P=0.698$, ns; Fig. 7). Thus, ant dipping was not influenced by the abundance of fruit as the chimpanzee staple food, and ant consumption remained relatively steady throughout the year.

[Figure 7 here]

\section{Night groups and consumption practices}

For 161 chimpanzee night groups, we were able to calculate the proportion of members with ant remains in their faeces (Fig. 8). In 32.5\% of night groups, all members had recently eaten ants, while in $26.3 \%$, none of the members had consumed them. In the remaining $41.3 \%$ of groups, some members had recently eaten ants, whereas others had not.

[Figure 8 here]

We split the results into monthly proportions (Fig. 9), which revealed a consistent pattern. Night groups always consisted of three fractions that were roughly equal across months: one in which all members had recently eaten ants, one in which nobody had recently eaten ants, and one fraction where some - but not all - members had recently eaten ants.

[Figure 9 here]

The monthly data were then summed up (Fig. 10). Accordingly, groups where everybody had recently fed on ants were found to be relatively small (mean 2.2 animals, 
median 1 , range $1-12, \mathrm{SD}=2.1, n=42$ ), as were groups were nobody had fed on the insects (mean 2.6 animals, median 2, range $1-13, \mathrm{SD}=2.5, n=52$ ). These groups did not differ in size (t-test, $P<0.20, \mathrm{~ns}$ ). In contrast, night groups where some members had and others had not fed on ants (mean 6.7 animals, median 5, range $2-17, \mathrm{SD}=3.9, n=66$ ) were significantly larger (t-test, $P<0.001$ ).

[Figure 10 here]

\section{DISCUSSION}

Our data demonstrate that Gashaka-Kwano chimpanzees eat army ants throughout the year. Despite considerable habitat seasonality (cf. Fig. 1) in terms of rainfall and ensuing plant cover and fruit availability (cf. Fig. 3), myrmecophagy is maintained at a practically constant and comparably elevated level (cf. Fig. 6a).

\section{Elevated levels of myrmecophagy through harvesting from nests}

That army ant eating is hardly affected by seasonality probably reflects the harvesting strategy. At some sites, chimpanzees collect ants from columns. However, harvest is low, since the chimpanzees use relatively short sticks and because the prey disperses rapidly (e.g., Bossou / Guinea, Humle and Matsuzawa, 2002). Moreover, although colonies forage and migrate by both day and night, workers minimize exposure to hot and arid conditions because of the risk of desiccation. The likelihood of encountering trails in daylight therefore drops dramatically during the dry season (Schöning et al., 2007; see also Koops et al., 2013). Gashaka-Kwano chimpanzees can nevertheless maintain elevated levels of myrmecophagy, because they directly exploit the underground burrows. This is evidenced by the fact that virtually all recovered dipping wands were found discarded at nest entrances (cf. Fig. 2). Given that at Gashaka army ants change their burrows every 2 weeks or so (Allon et al., 
2012), the apes have to detect new colonies recurrently, despite a relatively low density of 1 per 1.3 ha. The apes seem to find them mostly opportunistically, at places where they spend relatively more time and/or where ant colony density is highest, given that burrows in forests or at the base of food trees are predominantly targeted (Pascual-Garrido et al., 2013).

\section{Fallback or preferred food?}

Our data suggest that army ants do not represent a fallback food. We reach this conclusion because rainfall and fruit abundance in the Gashaka-Kwano habitat are strictly seasonal (cf. Fig. 3) while myrmecophagy is practically independent from the availability of fruit as the preferred staple food (cf. Fig. 5, Fig. 7). It seems that chimpanzees eat army ants every couple of days or so, with roughly the same high frequency (cf. Fig. 6a) and quantity (cf. Fig. 6b). While faeces with many ant remains are most prevalent during March-April, this is the peak fruit period, a fact that again contradicts the fallback hypothesis. The antdipping wands that help chimpanzees to access these resources are, as expected, likewise manufactured rather steadily (cf. Fig. 4).

Moreover, the sustained rates of ant gathering manifest themselves in the composition of night groups, as these, across different months, always consisted of three fractions (cf. Fig. 8): one in which all members had recently eaten ants (mean 2.2 animals), one in which nobody had recently fed on them (mean 2.6 animals), and a mixed fraction that, on average, was considerably larger (mean 6.7 animals; Fig. 10). The all-or-nothing groups are smaller, because, by definition, they include sleeping sites of single individuals $(n=45,28.0 \%)$ who are either ant-eaters or non-eaters. Moreover, in a small party of, for example, 2 animals it is more likely to have both individuals feeding, or both not feeding on 
ants. The odds of all feeding or non-feeding in a larger party are reduced because not everybody might end up ant-dipping, if dominant individuals have priority access to the insect nest or if its members are spread out and engaging in different activities. Nonetheless, these dynamics are roughly the same during each month (cf. Fig. 9), which provides additional support for a steady rate of army ant consumption in the chimpanzee community.

Admittedly, to exclude a role as fallback food, the crucial test question is not whether insect consumption is constant. Instead, we have to ascertain whether insect gathering goes up when consumption of preferred foods goes down. We do not have direct data for this. However, sizes of night groups can serve as a proxy for the level of competition over preferred foods that individual chimpanzees experience. Accordingly, night groups should become smaller when preferred foods are less abundant. Such a significant negative correlation is indeed found (cf. Fig. 3), while the level of myrmecophagy does not increase.

The Gashaka data therefore do not support the fallback hypothesis. This leaves the possibility that army ants constitute a preferred food. In fact, the consumption patterns seem to fulfill several criteria for preferred food (see Introduction): army ants are selected disproportionately often, relative to abundance while gathering requires long searches coupled with short processing time, given the special harvesting adaptation of accessing them through tools (cf. Harrison and Marshall, 2011).

\section{Nutritional values of preferred food}

For all that, the classification of primate diets into preferred and fallback foods tells us little about the actual nutritional value of a particular ingested item. 
As for preferred plant food, nutritional analyses revealed that Gashaka-Kwano chimpanzees are selective with respect to fruit quality (Hohmann et al., 2006a; Sommer et al., 2011). Thus, food plants contain higher amounts of sugar and fat as well as lower proportions of dry matter, which means that food items have higher water content. Chimpanzees also choose fruit with lower proportions of fibre. Accordingly, the apes seem to maximize the input of macronutrients and minimize ingestion of non-digestible fibrous parts. Moreover, the levels of phenol and total tannin are 2-3 times higher in non-food items, suggesting that the chimpanzees minimize ingestion of anti-feedants.

These findings again support the general idea that preferred foods drive harvesting adaptations (Lambert, 2007; Marshall and Wrangham, 2007). Accessing preferred fruit does not only require selectivity, but the chimpanzees at Gashaka also invest time to remove seeds from fruit and thus in digestion. Moreover, to reduce intra-group competition, chimpanzees maintain a social structure of fission-fusion. The resulting levels of gregariousness at Gashaka-Kwano, as measured through the size of night groups, are comparably low (Hohmann et al., 2006a).

We do not have comparable nutritional data for army ants. Still, with respect to insects in general, a scheme developed by Rothman et al. (2014) classifies their potential contribution to primate diets as follows: (a) staples (eaten daily and providing the major macronutrients and energy, chiefly protein and fat); (b) complements (supplies nutrients not sufficiently available in other portions of the diet; e.g. gum may contribute energy, while insects contribute protein); (c) supplements (provides a single nutrient deficient in the staple, e.g. vitamin $\mathrm{B}_{12}$ ); (d) replacements (opportunistic consumption when availability is high, e.g. during outbreaks of locusts, caterpillars or scale insects). The authors stress that, 
while insects are good sources of protein, fat and micronutrients, these invertebrates "are 'small packages' of nutrients and so nutritional payoffs from eating insects are limited unless primates are small, or they can consume sufficient quantities" (Rothman et al., 2014: 61).

Army ant meals of chimpanzees do not fulfill the criteria of staples or replacements, but potentially the categories of supplements or complements. The particular type of targeted micro- or macronutrient is unknown. However, given that Gashaka-Kwano chimpanzees select fruit with high sugar and fat content, they may well be in need to maximise these macronutrients. Moreover, particularly protein-rich herbs such as Haumania liebrechtsiana are absent from this site (Sommer et al., 2011). These findings sit well with nutritional data for Dorylus ants collected at Gombe / Tanzania, suggesting that "insectivory is potentially a viable (albeit time consuming) strategy to acquire animalsource proteins and fat" (O'Malley and Power, 2012: 500; see also Deblauwe and Janssens, 2008).

The problem for large-bodied primates lies with the only small amount of nutrients an ant-meal can provide. However, at Gashaka, nutritional yield may indeed be significant (cf. Rothman et al., 2014), given that experiments indicate that an ant dipping session provides a chimpanzee with 11,217 ants of $12.9 \mathrm{mg}$ of dry weight (Allon et al., 2012). The species exclusively eaten at Gashaka, Dorylus rubellus, might be particularly aggressive, thus resulting in greater harvesting success than elsewhere.

Finally, it should be mentioned that the dichotomy of fallback versus preferred foods is also reflected in two hypotheses that focus on the relative value of resources (Fox et al., 1999). The necessity hypothesis states that tool-assisted ant harvesting is a response to the 
scarcity of preferred food while the opportunity hypothesis predicts that sustained patterns of tool-assisted insect gathering are triggered by high encounter rates with the insects. Our research supports the opportunity hypothesis, because it suggests that Dorylus rubellus are not actively searched for but opportunistically encountered (Pascual-Garrido et al., 2013). Moreover, they are not only far more abundant than the other Dorylus species at the site, but perhaps more easily available because of an enhanced aggressive-defensive nature (Allon et al., 2012).

Our results do not necessarily confirm findings for other sites where chimpanzees eat army ants. For example, at Seringbara / Guinea (Koops et al., 2013) and Goualougo / Congo (Sanz and Morgan 2013) there was likewise no negative correlation between army ant gathering and fruit availability, but harvesting was positively related to rainfall. In La Belgique / Cameroon, ant eating increased in periods of succulent fruit scarcity, but did not correlate with rainfall (Deblauwe, 2009: 241).

Such variation is likely due to different ecologies and / or cultural factors (Schöning et al., 2008; Koops et al., 2015). Further fine-tuned data collection and cross-site comparisons are needed to detect particular underlying causes.

\section{Social dimensions of diet?}

Chimpanzee researchers maintain widespread consensus that regional variation in extractive foraging for insects, apart from ecological and nutritional causes, also reflects cultural dimensions, because social context may influence the acquisition and maintenance of skills and harvesting techniques (e.g., Hedges and McGrew, 2012; Webster et al., 2014; Hashimoto et al., 2015). Thus, "through immigration, social transmission, and subsequent 
'education' through generations, sets of neighbouring chimpanzee communities can come to comprise 'cultural zones' " (Biro et al., 2003, p. 222).

As a consequence, while chimpanzees are able to survive in diverse habitats by adapting the portfolio of their diet to local conditions, their food regime - including techniques of procurement - is likely to reflect certain arbitrariness (e.g., Luncz et al., 2012; O'Malley et al., 2012; Koops et al., 2015). For example, even if chimpanzees find an alternative equally effective, they may copy the dominant technical solution to obtain food that is prevailing in their group (Whiten et al., 2005).

Therefore, apart from satisfying nutritional needs, diets encompass a social dimension. This is well understood for human populations. For instance, whether or not certain types of meat are eaten (beef, pork, dog, monkeys) can serve as an important signifier of group identity (Douglas, 1966; Nyanganji et al., 2011). The same dynamic may apply to chimpanzee communities - quite independent from whether or not the prevalence of extractive foraging is brought about by opportunity or necessity (Fox et al., 1999) or reflects a strategy to acquire fallback food or preferred food (Harrison and Marshall, 2011).

Which incentives could entice chimpanzees to do certain things (i.e., follow prescriptions) or not do others (i.e., follow proscriptions)? Such "irrational conformist behaviour" (Hopper et al., 2011: 1200) might strengthen group cohesion. Social anthropologists assert that identity evolves when humans adopt one another's culture through mimesis, while simultaneously constructing mental images of alterity (otherness) (Taussig, 1993). Chimpanzees might well develop similar dichotomies of " 'us' versus 'them' " (McGrew, 2004: 29), given that their territoriality often leads to lethal intercommunity encounters, which are driven by such distinctions (Mitani et al., 2010). 
Where does this leave us with respect to the Gashaka-Kwano chimpanzee community, which maintains sustained levels of army ant eating while ignoring termites? We cannot currently exclude that the absence of termite fishing reflects subtle environmental constraints, e.g., because mound density is low (Fowler et al., 2011). On the other hand, Gashaka-Kwano chimpanzees fish for wood-boring arboreal ants, an extraction activity intrinsically similar to the exploitation of termites (ibid.). The insects are invisible in both cases and the probing tools require pliability. However, the technology of fine ant-fishing tools does not double for termite-fishing. Similarly, Camponotus brutus ants are eaten in the Mitumba community of Gombe / Tanzania, but not in the neighbouring Kasekela community, who nevertheless consume smaller and less palatable Camponotus species (O'Malley et al., 2012).

Is it possible that community members do not eat termites, because "it is not something that is done here" (McGrew, 2004). The non-consumption of a perfectly edible food-item may thus reflect a "taboo" that comes at some cost. Similarly, army ant gathering is associated with painful bites, and self-experiments (cf. Allon et al., 2012) suggest that the highly chitinous insects do not taste well, compared to smaller arboreal ants and termites. Interestingly, group identity in humans is known to be closely tied to costly and thus honest signals by members of the community (Sosis, 2005).

While we do not have sufficient data for Nigeria, such speculations about social identity based on community-dependent behavioural uniformity are open to empirical testing. The principal method would be to document natural instances of "acculturation", when female chimpanzees transfer from their natal into a neighbouring community (Biro et al., 2003; McGrew, 2004; Luncz et al., 2012). In any case, non-nutritional aspects of food 
acquisition, including insectivory, merit further exploration, not least because they play a role in traditional human rituals (Bodenheimer, 1951).

\section{ACKNOWLEDGMENTS}

The Nigeria National Parks Service granted a research permit to the Gashaka Primate Project (GPP) and Gashaka Gumti National Park provided logistical support. Research was enabled by local field assistants (Hammaunde Guruza, Maigari Ahmadu, Buba Hammaselbe, Bobbo Buba, Buba Bello, Felix Vitalis), and earlier work of students (Andrew Fowler, Darren Ellis, George Nodza, Sandra Tranquilli). GJ was supported by the Fundação para a Ciência e Tecnologia / Portugal. APG is grateful to The Leverhulme Trust / UK for providing an Early Career Fellowship during the revision stage of this manuscript. GPP received its core funding through the Nigeria Biodiversity Programme of the North of England Zoological Society, Chester Zoo / UK.

\section{LITERATURE CITED}

Allon O, Pascual-Garrido A, Sommer V. 2012. Army ant defensive behaviour and chimpanzee predation success: Field experiments in Nigeria. J Zool 288:237-244

Basabose AK. 2002. Diet composition of chimpanzees inhabiting the montane forest of Kahuzi, Democratic Republic of Congo. Am J Primatol 58:1-21.

Biro D, Inoue-Nakamura N, Tonooka R, Yamakoshi G, Sousa C, Matsuzawa T. 2003. Cultural innovation and transmission of tool use in wild chimpanzees: evidence from field experiments. Anim Cogn 6:213-223.

Bodenheimer FS. 1951. Insects as human food. The Hague: Dr W Junk.

Boesch C, Hohmann G, Marchant, LF, editors. 2002. Behavioural diversity in chimpanzees and bonobos. Cambridge: Cambridge University Press. 
Bogart SL, Pruetz JD. 2011. Insectivory of savanna chimpanzees (Pan troglodytes verus) at Fongoli, Senegal. Am J Phys Anthropol 145:11-20.

Caldecott J, Miles L, editors. 2005. World Atlas of Great Apes and their Conservation. Los Angeles: University of California Press.

Collins A, McGrew WC. 1987. Termite fauna related to diffences in tool-use between groups of chimpanzees. Primates 28:457-471.

Deblauwe I. 2009. Temporal variation in insect-eating by chimpanzees and gorillas in southeast Cameroon: extension of niche differentiation. Int J Primatol 30:229-252.

Deblauwe I, Janssens GP. 2008. New insights in insect prey choice by chimpanzees and gorillas in southeast Cameroon: the role of nutritional value. Am J Phys Anthropol $135: 42-55$.

Douglas M. 1966. Purity and danger: an analysis of the concepts of pollution and taboo. London: Routledge \& Kegan Paul.

Dunn A. 1999. Gashaka Gumti National Park: a guidebook. Lagos: GGNP/NCF/WWF-UK. Dutton P, Chapman H. 2015. Dietary preferences of a submontane population of the rare Nigerian-Cameroon chimpanzee (Pan troglodytes ellioti) in Ngel Nyaki Forest Reserve, Nigeria. Am J Primatol 77:86-97.

Fowler A, Pascual-Garrido A, Buba U, Tranquilli S, Akosim C, Schöning C, Sommer V. 2011. The material culture of Nigerian chimpanzees. A contribution to cultural primatology. In: Sommer V, Ross C, editors. Primates of Gashaka. Socioecology and conservation in Nigeria's Biodiversity Hotspot. New York: Springer. p 451-492.

Fowler A, Sommer V. 2007. Subsistence technology in Nigerian chimpanzees. Int J Primatol 28:997-1023. 
Fox EA, Sitompul AF, van Schaik CP. 1999. Intelligent tool use in wild Sumatran orangutans. In: Parker ST, Mitchell RW, \& Miles HL, editors. The mentalities of Gorillas and Orangutans. Cambridge: Cambridge University Press. p. 99-116.

Harrison ME, Marshall AJ. 2011. Strategies for the use of fallback foods in Apes. Int J Primatol 32:531-565.

Hashimoto C, Furuichi T, Tashiro, Y. 2000. Ant dipping and meat eating by wild chimpanzees in the Kalinzu Forest, Uganda. Primates 41:103-108.

Hashimoto C, Isaji M, Koops K, Furuichi T. 2015. First records of tool-set use for ant-dipping by Eastern chimpanzees (Pan troglodytes schweinfurthii) in the Kalinzu Forest Reserve, Uganda. Primates 56:301-305.

Hedges S, McGrew WC. 2012. Ecological aspects of chimpanzee insectivory in the Budongo Forest, Uganda. Pan African News 19:6-7.

Hohmann G, Fowler A, Sommer V, Ortmann S. 2006a. Frugivory and gregariousness of Salonga bonobos and Gashaka chimpanzees: the abundance and nutritional quality of fruit. In: Hohmann G, Robbins M, Boesch C, editors. Feeding ecology in Apes and other Primates. Cambridge: Cambridge University Press. p 123-159.

Hohmann G, Robbins M, Boesch C. 2006b. Feeding ecology in Apes and other Primates. Cambridge: Cambridge University Press.

Hopper LM, Schapiro SJ, Lambeth SP, Brosnan SF. 2011. Chimpanzees' socially maintained food preferences indicate both conservatism and conformity. Anim Behav 81:11951202.

Humle T, Matsuzawa T. 2002. Ant-dipping among the chimpanzees of Bossou, Guinea, and some comparisons with other sites. Am J Primatol 58:133-148. 
Koops K, McGrew WC, Matsuzawa. 2013. Ecology of culture: do environmental factors influence foraging tool use in wild chimpanzees, Pan troglodytes verus? Anim Behav 85:175-185.

Koops K, Schöning C, Isaji M, Hashimoto C. 2015. Cultural differences in ant-dipping tool length between neighbouring chimpanzee communities at Kalinzu, Uganda. Sci Rep $5: 12456$

Lambert JE. 2007. Seasonality, fallback strategies, and natural selection: a chimpanzee and cercopithecoid model for interpreting the evolution of hominin diet. In: Ungar PS, editor. Evolution of the human diet: the known, the unknown, and the uknowable. Oxford: Oxford University Press. p. 324-343.

Leighton M, Leighton DR. 1982. The relationship of size and feeding aggregate to size of food patch: Howler monkey Alouatta palliata feeding in Trichilia cipo trees on Barro Colorado Island. Biotropica 14:81-90.

Luncz L, Mundry R, Boesch C. 2012. Evidence for cultural differences between neighboring chimpanzee communities. Curr Biol 22:922-926.

Marshall AJ, Wrangham RW. 2007. Evolutionary consequences of fallback foods. Int J Primatol 28:1219-1235.

McGrew WC. 1992. Chimpanzee material culture. Implications for human evolution. Cambridge: Cambridge University Press.

McGrew WC. 2004. The cultured chimpanzee: reflections on cultural primatology. Cambridge: Cambridge University Press.

McGrew WC, Tutin CEG, Baldwin PJ. 1979. Chimpanzees, tools and termites: cross-cultural comparisons of Senegal, Tanzania, and Rio Muni. Man 14:185-214. 
McLennan MR. 2011. Tool-use to obtain honey by chimpanzees at Bulindi: new record from Uganda. Primates 52:315-322.

Mitani JC, Amsler SJ, Sobolewski ME. 2010. Chimpanzee minds in nature. In: Lonsdorf EV, Ross SR, Matsuzawa T, editors. The mind of the chimpanzee: ecological and experimental perspectives. Chicago: University of Chicago Press. p. 181-191.

Morgan B, Adeleke A, Bassey T, Bergl R, Dunn A, Gadsby E, Gonder K, Greengrass E, Koutou Koulagna D, Mbah G, Nicholas A, Oates J, Omeni F, Saidu Y, Sommer V, SunderlandGroves J, Tiebou J, Williamson L. 2011. Regional Action Plan for the Conservation of the Nigeria-Cameroon Chimpanzee. IUCN/SSC Primate Specialist Group, Gland, Switzerland and Zoological Society of San Diego / CA, USA.

Nishida T, Hiraiwa M. 1982. Natural history of a tool-using behaviour by wild chimpanzees in feeding on wood-boring ants. J Hum Evol 11:73-99.

Nishie H. 2011. Natural history of Camponotus ant-fishing by the M group chimpanzees at the Mahale Mountains National Park, Tanzania. Primates 52:329-342.

Nyanganji G, Fowler A, McNamara A, Sommer V (2011). Monkeys and apes as animals and humans. Ethno-primatology in Nigeria's Taraba region. In: Sommer V, Ross C, editors. Primates of Gashaka. Socioecology and conservation in Nigeria's biodiversity hotspot. New York: Springer. p 101-134.

O’Malley RC, McGrew WC. 2014. Primates, insects and insect resources. J Hum Evol 71:1-3. O'Malley RC, Power ML. 2012. Nutritional composition of actual and potential insect prey for the Kasekela chimpanzees of Gombe National Park, Tanzania. Am J Phys Anthropol 149:493-503.

O'Malley RC, Wallauer W, Murray CM, Goodall J. 2012. The appearance and spread of ant 
fishing among the Kasekela chimpanzees of Gombe: a possible case of intercommunity cultural transmission. Curr Anthropol 53:650-663.

Pascual-Garrido A, Buba U, Allon O, Sommer V. 2013. Apes finding ants: Predator-prey dynamics in a chimpanzee habitat in Nigeria. Am J Primatol 75:1231-1244.

Pascual-Garrido A, Buba U, Nodza G, Sommer V. 2012. Obtaining raw material: Plants as tool sources for Nigerian chimpanzees. Folia Primatol 83:24-44.

Pruetz JD. 2006. Feeding ecology of savanna chimpanzees (Pan troglodytes verus) at Fongoli, Senegal. In: Hohmann G, Robins MM, Boesch C, editors. Feeding ecology in Apes and other Primates: Ecological, Physical and Behavioral Aspects. Cambridge: Cambridge University Press. p. 161-182.

Reynolds V, Plumptre AJ, Greenham J, Harborne J. 1998. Condensed tannins and sugars in the diet of chimpanzees (Pan troglodytes schweinfurthii) in the Budongo Forest, Uganda. Oecologia 115: 331-336.

Rothman JM, Raubenheimer D, Bryer MAH, Takahashi M, Gilbert CC. 2014. Nutritional contributions of insects to primate diets: implications for Primate evolution. J Hum Evol 71:59-69.

Sanz CM, Deblauwe I, Tagg N, Morgan D. 2014. Insect prey characteristics affecting variation in chimpanzee regional tool use. J Hum Evol 71:28-37.

Sanz CM, Morgan DB. 2013. Ecological and social correlates of chimpanzee tool use. Philos T Roy Soc B 368: 20120416.

Schöning C. 2005. The driver ants of Mount Kenya. SWARA. Apr-Jun. p 32-37

Schöning C, Ellis D, Fowler A, Sommer V. 2007. Army ant prey availability and consumption by chimpanzees at Gashaka (Nigeria). J Zool 271:125-133. 
Schöning C, Humle T, Möbius Y, McGrew WC. 2008. The nature of culture: Technological variation in chimpanzee predation on army ants revisited. J Hum Evol 55: 48-59.

Sommer V, Adanu J, Faucher I, Fowler A. 2004. The Nigerian chimpanzee (Pan troglodytes vellerosus) at Gashaka: Two years of habituation efforts. Folia Primatol 75: 295-316.

Sommer V, Bauer J, Fowler A, Ortmann S. 2011. Patriarchal chimpanzees, matriarchal bonobos. Potential ecological causes of a Pan dichotomy. In: Sommer V, Ross C, editors. Primates of Gashaka. Socioecology and conservation in Nigeria's biodiversity hotspot. New York: Springer. p 417-450.

Sommer V, Buba U, Jesus G, Pascual-Garrido A. 2012. Till the last drop. Honey gathering in Nigerian chimpanzees. Ecotropica 18:55-64.

Sommer V, Ross C. 2011a. Primates of Gashaka. Socioecology and conservation in Nigeria's biodiversity hotspot. New York: Springer.

Sommer V. Ross C. 2011b. Exploring and protecting West Africa's primates. The Gashaka Primate Project in context. In: Sommer V, Ross C, editors. Primates of Gashaka. Socioecology and conservation in Nigeria's biodiversity hotspot. New York: Springer. p 1-37.

Sosis R. 2005. Does religion promote trust? The role of signaling, reputation, and punishment. Interdisc J Res Relig 1:1-30.

Stanford CB, Nkurunungi JB. 2003. Behavioral ecology of sympatric chimpanzees and gorillas in Bwindi Impenetrable National Park, Uganda: Diet. Int J Primatol 24:901918.

Swenson JE, Jansoon A, Riig R, Sandergren F. 1999. Bears and ants: myrmecophagy by brown bears in central Scandinavia. Can J Zool 77:551-561. 
Takemoto H. 2000. The seasonal change in feeding behavior of chimpanzees caused by the seasonal change of food availability. Reichorui Kenkyu [Primate Research] 16:280 (In Japanese).

Taussig M. 1993. Mimesis and Alterity. New York: Routledge.

Teleki G. 1974. Chimpanzee subsistence technology: materials and skills. J Hum Evol 3:575594.

Webster TH, McGrew WC, Marchant LF, Payne CLR, Hunt KD. 2014. Selective insectivory at Toro-Semliki, Uganda: comparative analyses suggest no 'savanna' chimpanzee pattern. J Hum Evol 71:20-27.

Whiten A, Horner V, de Waal FBM. 2005. Conformity to cultural norms of tool use in chimpanzees. Nature 437:737-740. 